\title{
Inner Landscapes: Transformative Learning Experiences of Canadian Education Interns in Greece
}

\author{
Eleoussa Polyzoi and Karen Magro \\ University of Winnipeg
}

\begin{abstract}
This exploratory study uses transformative learning theory as a lens to interpret and understand the challenges and successes experienced by education students who elect to teach or intern abroad. Transformative learning is a deeper-level learning that challenges learners to understand themselves and their world in new, more nuanced ways. We explore frames of teaching and learning from multiple lenses. Elements of the educational internship experience that emerged from students who participated in this study include initial apprehension, disbelief, and even fear; a disorienting dilemma or incongruent experience within the new school cultural context; a re-evaluation of their frames of reference, and a final emergence of more integrative, inclusive senses of self as "teacher" and "learner." Transformative learning theory can serve both as a conceptual framework for understanding the experiences of students and as a means of suggesting ways in which educational outcomes can be better designed with a transformative intent in mind. We then present implications for teaching and learning and suggestions for future studies.
\end{abstract}

Keywords: international experience; preservice teachers; internship; transformative learning; frames of reference

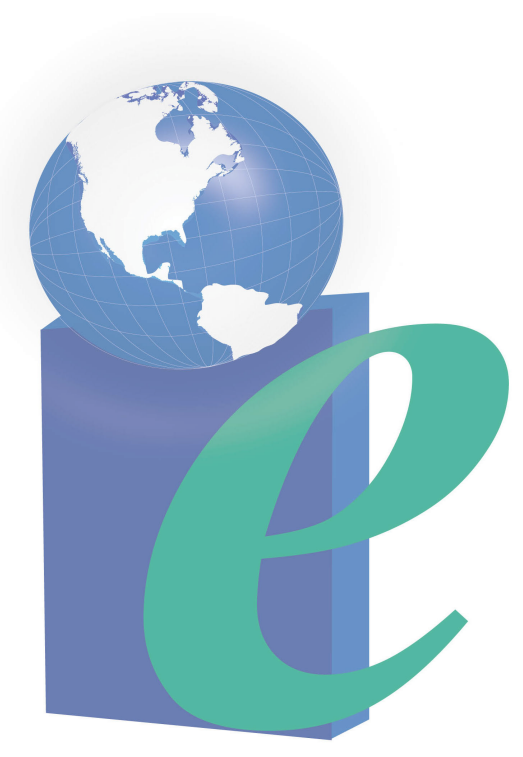




\section{Transformative Learning Theory}

Mezirow's $(1981,2000)$ theory of transformative learning can be a particularly useful framework for exploring and understanding the experiences of students teaching abroad, who experience a sense of "cultural disequilibrium," encountering feelings of marginalization and navigating new educational and cultural terrain involve learning processes. For Mezirow, learning not only involves gaining new information, but also fundamental change must in some way be part of what one has learned. This involves transforming the way we understand and interpret our world through a critical reflection of our assumptions and beliefs. Learning also involves emotional processes that result in a shift in self-perceptions and in how others are perceived. Learning "is understood as the process of using a prior interpretation to construe a new or revised interpretation of the meaning of one's experience in order to guide future action" (Mezirow, 1990, p. 162). Through critical reflection, individuals may begin to reassess their assumptions and perceptions. Mezirow (1990) describes the process of perspective transformation as

the process of becoming critically aware of how and why our presuppositions have come to constrain the way we perceive, understand, and feel about our world; changing these structures of habitual expectations to make possible a more inclusive, discriminating, and integrating perspective; and finally, making choices or otherwise acting upon these new understandings. (p. 14)

The change in frames of reference that many individuals experience may predispose them to feeling a sense of initial discomfort, enhanced vigilance, and uncertainty. Boyd and Myers (1988) refer to this as akin to a grieving process. They explain,

At its core, transformative learning theory is elegantly simple. Through some event, which could be as traumatic as losing a job or as ordinary as an unexpected question, an individual becomes aware of holding a limiting or distorted view. If the individual critically examines this view, opens herself to alternatives, and consequently changes the way she sees things, she has transformed some part of how she makes meaning out of the world. (Boyd \& Myers, 1988, p. 271)

From Mezirow's (1990) perspective, the help of a skillful teacher, mentor, and counselor can help guide the individual so that they are able to find alternative ways of thinking and ultimately acting. It is through self-disclosure and dialogue that significant personal learning is more likely to take place.

Specifically, Mezirow's (1981, 2000, 2012) work, rooted in constructivist and humanistic traditions, maintains that each person interprets the world in unique ways and that our assumptions often go unchallenged. A disorienting dilemma or incongruent experience, however, provides the catalyst for change, throwing a person off balance and putting into motion a series of stages that lead to a reformulation of their worldview. These stages include (a) selfexamination, (b) critical assessment of assumptions, (c) a recognition that others have shared similar discontentment and transformations, (d) an exploration of new values and actions, (e) development of a plan for action, (f) acquisition of knowledge and skills for implementing the plan, (g) execution of the plan, (h) development of competence and self-confidence in the new roles, and, finally, (i) a re-integration into one's life on the basis of conditions defined by one's new perspective. 
Mezirow (2000) acknowledges that the stages of perspective transformation may vary, depending on individual differences and experiences; the changes can also be sudden or incremental "involving a progressive series of transformations in related points of view" (p. 21). Mezirow also notes that individuals who are more willing to engage in the process of critical reflection and dialogic discourse display many of the qualities associated with emotional intelligence-emotional maturity, empathy, patience, control, optimism, skill in dealing with relationships, and the ability to handle stress in productive ways (p. 290). The work of theorists such as Brookfield (2000), Cranton (2006), Dirkx (2012), Daloz (2000), King, 2005, O’Sullivan, Morrell and O'Connor (2002), and Taylor and Cranton (2012) have built on Mezirow's theory by highlighting key factors that can influence the process of transformative learning. Collectively, these theorists have emphasized that factors such as the readiness of the learner, personality traits and learning styles; the cultural and socio-economic background of the learner; the educator's ability and interest in fostering transformative learning in educational contexts; and the nature of time and change as they relate to adult development all impact the process of learning. No less important are emotional and social literacies: motivation, resilience, interpersonal effectiveness, critical thinking, and cultural awareness. Other theoretical perspectives have offered additional insight into the learners' experiences. For example, literacy education for Freire (1997) goes beyond teaching functional reading skills and moves toward helping the disenfranchised gain a critical awareness of the social and political systems around them that may be contributing to inequality and oppression. From this perspective, learners can develop the ability to reflect upon the social, political, cultural, and economic contexts that shape their lives in significant ways. They may feel empowered to activate change in their lives.

\section{The Context}

This qualitative study examines, using the framework of transformative learning theory, the experiences of education student interns from the University of Winnipeg (UW), in Manitoba, Canada, who have taught abroad in Athens, Greece. In particular, the earlier stages described in Mezirow's $(1981,2000)$ theory of perspective transformation provide a unique lens through which the learners' experiences can be more clearly understood. The challenges and successes of preservice teachers who are interning abroad are not well understood within the context of transformative learning. We hope this study can shed some light on these experiences by examining student teachers' journal reflections, observations, and insights.

\section{ACS-Athens School}

In 2007, the UW and the American Community School (ACS) of Athens, an accredited Kindergarten-to-Grade-12 International Baccalaureate (IB) school in Greece, signed a memorandum of understanding inviting UW education students in the final year of their degree program to complete a 5-week practicum as interns at ACS-Athens.

ACS-Athens is an international school founded in 1949 to serve the families of the newly established American military base in Greece. The school serves the children of the American, international, and local Greek communities and embraces American educational philosophy, principles, and values. Currently, there are almost 800 students enrolled, representing over 45 countries. Approximately half of the students are American citizens of Greek origin; the remaining students are from the Middle East, Turkey, Canada, Africa, Europe, and People's Republic of China. Students are typically children of diplomats, chief executive officers, 
academics, government officials, and businessmen. ACS-Athens is accredited by the Middle States Association of Schools and Colleges as well as by the International Baccalaureate Organization, and it is located in the Halandri suburb of Athens, Greece.

As a state-of-the-art facility, ACS-Athens is a full capacity, wireless campus with interactive boards in all classrooms and laboratories. It has an extensive library containing the largest collection of English language books in Greece, numerous fully equipped science laboratories, a large professional-quality theatre, a fine-arts classroom suite, and a modern music room. The school also has outdoor basketball, volleyball, and tennis courts, as well as a large gymnasium, a weight-training room, and an Olympic-size swimming pool. Included in the staff are 80 teachers, 63 of whom have Master's degrees and four of whom have doctorates. Teacherstudent classroom ratios range from $1: 15$ to $1: 20$. Several teachers are accomplished authors in their own right, having published books in the fields of mathematics, history, poetry, counseling, leadership, and linguistics. The physics teacher is the author of the International Baccalaureate text in Physics used by IB schools throughout the world. ACS-Athens has an outstanding record of student placement following graduation, with over $90 \%$ of graduates placing in top universities around the world.

As a premier school in Greece, ACS-Athens is known for its numerous program initiatives that promote innovative teaching and learning, including a Summer Institute on Academic Leadership, a major Newscoop student journalism project affiliated with Harvard University, and its award-winning Institute for Creative and Critical Thinking. This program offers a unique, educational experience to students enrolled at ACS-Athens who aspire to become leaders in science, technology, business, government, education and community affairs, and the arts.

\section{The Study}

\section{Participants in the UW-ACS-Athens Internship Program}

Twenty UW education students (17 female and 3 male) participated in a 5-week internship at ACS-Athens over a 6-year period. All students were enrolled in their final year of the 5-year Education Program at the UW. They were drawn equally across early-, middle-, and senior-year streams, with teachable majors ranging from English language arts, social studies, and biology to theatre, history, mathematics and physical education. All were Canadian students in their early 20's who excelled in their teachable subjects; many had been awarded scholarships in Manitoba for their academic excellence. Candidates for the internship were accepted based on a variety of criteria including a GPA of 3.5/4 or higher, demonstrated pedagogical skills as confirmed by their faculty supervisor and cooperating teacher evaluations from previous placements in Winnipeg schools, and leadership skills. Additional talents that students had (e.g., in music, sports, or the performing arts) were also considered.

One of the requirements of the internship was for student teachers to reflect on and record their experiences in journals (2-3 pages in length) at the conclusion of their internship. They were encouraged to be as analytical and reflective as possible in their writing: "Describe something you observed or experienced at ACS-Athens that stood out for you, that was unique, that made you think about something you hadn't considered before, that provided some insight that impressed you, that was different than anything you had experienced before." Informal 
consent was given by the participants for publication of any articles emanating from their reflective journals.

\section{Methodology: Narrative Inquiry}

This qualitative study draws on phenomenography and narrative inquiry (Dominice, 2000; Merriam \& Associates, 2002; Karpiak, 2003; Lincoln \& Guba, 1985; Van Manen, 1997). The use of journal reflections and personal narratives as important instruments in collecting qualitative data has been studied extensively in recent years. Dominice (2000) notes that a richer understanding of the dynamics of adult learning can emerge through the analysis of autobiography, journals, and critical incident reflections. Merriam and Associates (2002) write that "in the same way that ethnography focuses on culture, a phenomenological study focuses on the essence of the structure of an experience. Phenomenologists are interested in showing how complex meanings are built out of simple units of direct experience" (p. 7). The experiences of individuals are "bracketed, analyzed, and compared" to identify the "essence of the phenomenon" (p. 8) that, in this study, is connected to student teachers working in an international practicum. What are their thoughts, expectations, and experiences? How do their beliefs, values, and perspectives of teaching guide their practice? Citing qualitative research analysis from Britzman (1998) and Dominice (2000), Karpiak (2003) emphasizes that adult learners who write about their experience can "embark on a process of personal self-reflection, self-definition, and meaning making that can transform their view of self and the world" (p.99). How have the student teachers' insights and actions regarding effective teaching and learning changed or transformed as a result of their international teaching experience? Have their beliefs about teaching and learning been confirmed or have they been modified or altered in different ways based on their new experiences? Britzman (1998) explains that there are three ways of telling one's story, which reflect three dimensions - the ethnographic (where the emphasis is on descriptive detail); the reflective (where the emphasis is on critical thinking and reflection), and the uncanny where more complex, conflicting thoughts, emotions, and experiences that have been dormant begin to emerge. In this study, approximately 50 pages of written journal reflections constituted the body of text that served as the basis for this study's exploratory analysis. Content was analyzed for recurrent themes that coalesced around each of the different phases of transformative learning identified by Mezirow (2000). Below is a summary of the analyses and subsequent subthemes that emerged. The quotes selected below were selected as the most representative of the participants' experiences and the most powerfully expressed. All names used are pseudonyms.

Position of the researchers. Eleoussa Polyzoi, a Professor of Education at the University of Winnipeg, collected the data set for this study. She has been the Coordinator of the international internship and students' Faculty Supervisor at ACS-Athens since the program's inception. She has spent two sabbatical years as Adjunct Professor at the University of Athens, Department of Psychology, conducting research in inclusivity in child care, educational change and innovation, and the teacher as leader. Karen Magro is an Associate Professor at the University of Winnipeg whose areas of research interest include adult development and transformative learning theory as applied to immigrant and refugee experiences. She is currently exploring the way experienced teachers integrate social justice themes in literacy education. A major focus of her research is to understand the specific personality of the learner and contextual factors that may contribute to transformative learning in secondary school and adult literacy settings. 


\section{Results: Education Interns Teaching Abroad: Understanding Their Experiences Through the Lens of Transformative Learning Theory}

The journeys of learning that many of the student teachers in this study embarked upon parallel key learning phases that Mezirow (1981) outlines in his theory of transformational learning. Their journal accounts highlighted the values, beliefs, and ideals that guided them as student teachers in making decisions. Student teachers typically negotiate new roles and responsibilities as they work to complete their professional degrees. Though their values guide their practice, educational interns also teach to conform to the standards and practices of their cooperating teachers, practicum supervisors, and professors (Kelly, 2012). As they navigate new teaching terrain, their cooperating teachers serve as important guides and mentors. Education interns who also teach abroad additionally face the challenge of adapting to a new culture, an unexplored city, and an unfamiliar school system. These "disorienting dilemmas" can create insecurity and discomfort.

\section{Phase 1: Initial Apprehension}

The first phase of the students' journey in this exploration was characterized by initial apprehension, self-doubt, and even fear. For Camille, the fear was breath-robbing, for Rebecca, it was coupled with a feeling of excitement at the prospect of new learning, and, for Lauren, it expressed itself as a hyper-vigilance and a realization that she was about to embark on a journey of self-discovery. She describes her fear of taking on her teaching responsibility as "gripping, incapacitating, tremor-inducing, breath-robbing, sleep-depriving, weeping-in-the-middle-ofclass-from-sheer-terror fear" (Lauren, journal, April 5, 2011). This fear alternated with the thrill and positive anticipation of the new challenge: "I felt a slight whooshing vacuum in its absence which was instantly filled with excitement, relief, and joy" (Lauren, journal, April 5, 2011).

\section{Flooding of my senses.}

When I arrived in Greece, all of my senses were completely turned up to the maximum. My eyes were constantly taking in the new surroundings, the sounds of the city filled my ears...There was a constant influx of new information flooding my senses. (Lauren, journal, March 27, 2011)

\section{Phase 2: A Disorienting Dilemma/Incongruent Experience Prompting Re-evaluation of One's Frame of Reference}

Once the interns had been introduced to their teacher mentors, had negotiated the teaching units for which they were responsible, and had observed a number of master teacher classes, they were assigned to their students. In reflecting on their experiences during the next 5 weeks, interns' journal entries were, almost without exception, grounded in expressions of a collision of value systems between the teaching skills, experiences, and knowledge that they had begun to develop at UW and the wisdom, experience, and master teaching skills demonstrated by their mentors at ACS-Athens. This series of discrepancies prompted a questioning of values and an accompanying re-evaluation of their frames of reference. The student teachers began to compare their prior knowledge of teaching, students, the process of learning, and the educational context with their new learning challenges.

Dalia responds to her first teaching evaluation initially with some trepidation. However, once it is received, she is able to "see" herself teaching through her mentor's eyes and to 
appreciate the detail "in real time" that the running record provided by her mentor affords her. The epiphany - that excellence is an approach not a destination - allows her to continuously improve and hone her craft. The holistic and humanistic perspective that many of the mentor teachers hold is balanced by their value for creative and critical thinking.

\section{Through my mentor's eyes}

The Head of the History/Humanities Department observed my teaching today.... I was filled with apprehension and anxiety.... She sat at the back of the classroom, occasionally smiled at me, and when the class ended, thanked me.... When I met with her later, she presented me with eight pages of notes and observations and another page of suggestions. She had recorded much of the dialogue and the action in the classroom. As I read through it, I could actually see myself teaching! It was remarkable. I could hear well-worded questions, I could sense the timing, and I could see where I should have reiterated, or waited, or asked, or let others speak. Rather than learn what she thought about my teaching, I actually got to observe myself!

She and I went over the notes, and we both worked in praise, contemplation, and suggestions. This was such an enjoyable and rewarding process. There was a heady exchange of ideas as we challenged or expanded on one another's insights and reflections. My observation had not been a test, but a learning experience, and I had not passed or failed-I had learned. This happened because at ACS, excellence is not an end point but a continual process, and it is a process that both teacher and student are committed to....Excellence is an approach not a destination. (Dalia, journal entry, May 10, 2008)

While teaching at ACS-Athens, Dalia misinterprets students' foreign comments "flying" around in the back of the classroom as purposeful interruption. She later realizes that the students were simply engaged in a heated argument over issues currently ravaging their respective native countries - a friendly altercation originally sparked by the lesson itself. She realizes the importance of giving voice to the immediate and unique personal perspectives of students who are "living" the history being addressed. She laments that historians do not have adequate tools to analyze "history in the making" constrained by the absence of hindsight.

\section{Lost in translation}

Today I was struck by the presumptions of my cultural perspective. Many of the students who attend ACS are not Greek. The diversity in any given classroom is remarkable. It is possible to have a student from every continent in any one class. Often, English is a second or third language for the students...

Even more incomprehensible are the experiences of my students. I have been struggling to smother the foreign comments that angrily fly at the back of one of my classes. You see, one student is from Albania, and, by choice, he sits near another student from Serbia. Both students had been forced to leave their countries because of the political instability of their homelands. As a Canadian History teacher, I floundered to address the root of their contentions. 
In after-class conversations, which the students were generous enough to share with me, I learned that the Serbian student had survived an American bombing in his home country, and was angry that the Albanians had occupied part of his country and wanted them to get out. The Albanian student insisted that the Serbians had asked them to come into Serbia to help maintain internal stability. I was unfamiliar with the specifics of the event, but I quickly learned that the contention would not be solved from a clear explication of the historical "facts." The problem was one of perspective. As a well-educated University of Winnipeg history major, I was fluent in the language of historical perspective, but as a Canadian, I was sorely inexperienced in modern warfare. This was both extremely fortunate and intellectually debilitating for me. All the history I taught or studied was history to me; I had not participated in it. Now I was confronted with history in the making. I cannot think of a more intimate brush with history than running for your life from the bombs of another country.

Today I realized that history is not static ...We practice history every day. I forgot this because explaining something as complicated as the loss of life and homeland only ever entered my realm of historical theories as intellectual entertainment. My students reminded me that history is not something I know-it is something I do. (Dalia, journal entry, May 18, 2008)

Early on, Dalia discovers that many of her students at ACS-Athens are from families of privilege. By comparison, the students she has taught in Canada came from lower socioeconomic backgrounds. Many of her students in Winnipeg came from single parent homes; some families faced psychological, situational, and financial barriers (Cross, 1981). Poverty and economic hardship, unsafe housing, poor health, a lack of access to healthy foods, and family conflict are barriers that can interfere with learning. She wonders how the ACS-Athens students' advantages will affect their learning, and in turn, her instruction.

\section{Her grandfather worked with Fidel Castro}

A passing acquaintance with the academic rigor of the IB program at ACSAthens did not prepare me for topics that sounded more like university course work than Grade 12 history. Hardly less impressive was the pedigree of the students. One boy, encouraged by my Cooperating Teacher, admitted that he was an English Lord and $46^{\text {th }}$ in line for the English throne. Understandably, this student's paper related to the monarchical history of Great Britain. I marvelled at the unique vantage points, as I realized that all the students had an intimate connection to their chosen topic. One student was researching Cuban history because her grandfather worked with Fidel Castro and she had access to numerous private, primary resources. Another was focusing on the Junta in Greece; her family knew former Prime Minister, George Panpandreou well. Children of various foreign diplomats and ambassadors researched topics that they too had direct links with through the work of their parents. I was overwhelmed by the historical consciousness of students who viewed current events as active participants, and I began to ask myself how this would affect my instruction. (Dalia, journal entry - April 26, 2008) 
Anne tries to reconcile the devaluation of homework that she encountered in Winnipeg schools with ACS-Athens' approach where homework is used strategically as a means to build on classroom learning in creative and expansive ways. Students are able to make text-to-self connections; literature and related texts are used to open a window to timely social, cultural, and political events.

\section{Building on classroom learning in creative ways}

I had been at ACS for a few days before meeting the Grade 7 classes in which I would spend the next month teaching. I was excited....The students had recently finished reading a series of utopian/dystopian novels (e.g., The Giver by Lois Lowry; Brave New World by Aldous Huxley; War of the Worlds by $\mathrm{H}$. G. Wells) and my host teacher was explaining the process they would follow to write a constitution for creating their own utopian school. The next day, I anticipated that the assignment would be re-explained and that I would then see the assignment in progress as students determined the general course and shape of their schools and begin planning particular clauses in their constitutions. Instead, the students came to class with rough drafts of their utopian schools, some as long as eight pages! I instinctively recoiled from this, not only because I am unaccustomed to students completing so much so quickly but also because I felt that, as a teacher, I had missed out on a significant part of the learning process.

In my previous teaching practica, homework had been kept to an extreme minimum and had been assigned only as a last resort if students had not been making diligent use of their class time.... [At ACS-Athens], I adapted to this unique teaching environment and learned to assign significant portions of work to be done at home and then build off of that work in more creative ways in the classroom. (Anne, journal entry, April 16, 2008)

Anne compares the negative elements of peer pressure, which she is accustomed to seeing in Canadian schools, with the more positive, energizing, and inclusive peer pressure, which she sees exemplified at ACS-Athens: students encouraging classmates to aspire to excellence in their Grade 10 American Studies class.

\section{Aspiring to excellence}

I have come to learn, through my own schooling, that social approval is how negative aspects of peer pressure drive certain children to make poor choices in life....However, throughout my teaching practicum at ACS, I have seen social pressure work in constructive and fascinating ways throughout both the student body and the community of teachers and school staff. Students are encouraged by their peers to challenge themselves in an academic environment, and the prevailing atmosphere is in accordance with the goals of the school. An example of this is the yearly mock trial in which the grade 10 American Studies class puts President Harry S. Truman on trial for "crimes against humanity." Throughout the days leading up to the trial, older students who have previously participated in the trial will randomly drill many of the witnesses (e.g., Albert Einstein, a Scientist on Radiation, A Citizen of 
Hiroshima, and Truman himself) to ensure that they have done their research and will accurately and realistically represent their historical character when called to the stand. This type of social pressure imparts energy to many learning situations and is the impetus for much of what the school excels at. As a teacher, I feel an almost tangible force pulling me along with the momentum of the school itself, and although I am accustomed to decrying the dangers of peer pressure, perhaps there is cause to recant. (Anne, journal entry, May 10, 2008)

Linda comments on the many dynamic and creative learning opportunities offered to students at ACS-Athens. In her reflection, she highlights the initiative of ACS-Athens and Harvard University's Newscoop Organization, which offers students the opportunity to write, edit, and produce video documentaries that address the most contested conflicts in modern history. Activities are completed in collaboration with other students throughout the world. In 2009, ACS-Athens students produced their first piece, a 26-minute documentary on the IsraeliPalestinian conflict that was covered nationally by the Greek television media, with rave reviews (Kelly, 2009, p. 28).

\section{Learning beyond the classroom}

Today, I witnessed what ACS is all about: educating students on worldwide issues through multiple entry points. Today, a group of Academy (high school) students presented a documentary that they scripted, edited, narrated, and researched. The documentary focused on the historic and current issues between Israeli and Palestinian peoples. The entire Academy was invited to watch the premiere of this documentary in the large theatre of ACS-Athens. Along with students, teachers, parents, and the national media, several ambassadors were present, including the Israeli, Palestinian, and United States of America ambassadors.

I was blown away by the complexity of the issues and how well and unbiased the documentary was presented. The students were truly aware of how sensitive the issue is and I believe they successfully presented these issues in an unbiased, realistic, and emotional light.

Not only was the documentary amazing, with evoking images, concise narratives, and well-researched information, but the students were asked to sit on a panel and answer difficult questions from audience members. I was incredibly impressed with how eloquently and coherently the students were able to answer these questions, offering intellectual answers, while keeping to the point. The students were well able to justify their decisions in making the documentary as well as remove their own opinions from the topic. (Linda, journal entry, April 19, 2010)

Camille, in poetic form, celebrates the creative energy found at ACS-Athens and eloquently expresses how the use of imagination, inspiration, and originality in her own teaching has transformed her sense of self as teacher and learner. 


\section{Creativity blooming riotously}

Creativity bloom riotously, the school whispered silently. Never had I felt so alive to inspiration... And because I was steeped in their example, I could not help but exhale it. It was unprecedented, and I wondered...how functioning in another environment would ever be possible for me again.

A sort of fresh and bittersweet pain followed me from moment into moment. It exploded in puffs. Each new present was the transformation from chrysalis to butterfly - the struggling emergence of a new self. (Camille, journal entry, May 8, 2008)

Jared was impressed by the wealth of creative classes available to students at the Academy (high school). For example, the unique Humanities course that he observed (combining social studies, art history, and English language arts), is designed for only the most dedicated Grade10 students.

\section{Sir Thomas Moore's Utopia}

The speed at which Humanities progressed was astounding. I recall students having to read Sir Thomas Moore's Utopia in just over a weekend, with a paper due not long after. Clearly not all assignments and works studied come and go as quickly as this, but it showed me that if you show students you expect a lot out of them, they will respond accordingly. I was able to peer-edit one Utopia personal essay and found it to be nearly impeccable. Even the class discussions were insightful and always productive. Teach a man to fish, and you will feed him for a lifetime. Treat students like smart, productive members of society, and they will act and become smart, productive members of society. The highest expectations seem to yield the highest results. (Jared, journal entry, April 26, 2013)

Dinah marvels at the unique elements of cross-curricular team teaching that she observed demonstrated by her mentors at ACS-Athens.

\section{Team teaching at its finest}

I feel privileged to have experienced the unique team-teaching Humanities courses offered to the students at ACS. These courses took team teaching one step further by combining not only the skills and experience of two master teachers but also the concepts and topics found in both history and literature. The notion of combining literature and history seemed like a natural grouping when I observed these classes during my stay at ACS....Jan and Kathy worked together flawlessly. Each teacher had her own role to play. During Jan and Kathy's class, both teachers were constantly focused on the material discussed. While Kathy would teach her material, Jan was a support not only to Kathy but also to the students. Keeping a written record of the class discussions and assignments on the computer, which projected onto the board, allowed the students to focus their attention on Kathy's main points. It also acted as a great study tool, allowing the students to reflect on what was discussed in class or, if they missed a class, to catch up on new ideas.... These unique combo classes demonstrated an array of techniques for classroom teachers to keep literacy at 
the forefront of their teaching. I look forward to bringing this idea of crosscurricular team teaching back to Winnipeg with me. It is evident by the large number of students registered and their constant engagement during class that these courses are of interest to many of our students today. (Dinah, journal entry, April, 2013)

Alice ponders the advantages of ACS-Athens' focus on student-centred learning and minimal use of the transmission model of teaching.

\section{Students taking learning into their own hands}

I was given the opportunity to chaperone the Grade 6 Annual Walk of Athens field trip....Having a Classical Studies minor, I was ready for the adventure. I was informed that the students would be taking charge of the field trip, following the ACS philosophy of inquiry-based learning. Each student was part of a larger learning group, which was assigned an historic monument to research and present to classmates. When we arrived at the monuments, the students became our tour guides and proceeded to describe the history, architecture, and mythologies associated with each archaeological site. We visited sites such as Hadrian's Library (132 AD)... the Roman Agora (on the north side of the Acropolis)... and the Tower of the Winds (50 BC).

This Annual Walk of Athens opened my eyes to the advantages of students taking learning into their own hands. Not only did the presenters learn about their own site or monument, but also they were attentive to what their peers presented and absorbed the knowledge being shared....I began to ponder how I, as a teacher, could bring inquiry and student-centered learning into my own classroom. In most science classrooms, the teacher often becomes the giver of knowledge and the students the receivers, but how can we change this view of teaching and learning? As an educator, I believe that this type of learning is essential to promote student engagement.... Students can "live" the subjects they are learning about in the world around them as an alternative to the traditional learning paradigm. (Alice, journal entry, April 28, 2010)

Katerina reflects on how awestruck she felt within the first few hours of working with the IB Grades 9 and 10 Theatre teacher at ACS-Athens. Hearing the "language of the theatre" used with such ease by the students at ACS, causes her to reflect.

\section{Breathtaking pieces of art}

Though I have completed three years of high-school theatre and three years in the Theatre Department at the University of Winnipeg, earning a major in Theatre, I had not been prepared for the magnitude of IB Theatre at ACSAthens. Stanislavsky's Method? Kabuki Theatre? Italian Arched Theatre? Lighting "booms" and gel slides? These were common topics of conversation with the junior and senior IB classes. Sofia [the IB teacher] talks the language of theatre, a language that I should be fluent in. It's an odd feeling being confused by the conversations of high schools students $100 \%$ of the time 
within a subject area that I am supposed to be an expert. Though my selfesteem took a hit, it has been so amazing to work with these students who love theatre as much as I do. These are students who want to go to university and study theatre. It was a critical experience to witness the senior IB students creating such breathtaking pieces of art on stage. (Katerina, journal entry, May $18,2013)$

The above observations reflect transformative learning themes. Experiential learning, critical reflection, discussion, collaboration, and the sharing of divergent perspectives provide an enriched learning context. This captures Wolk's (2009) emphasis on the importance of a dynamic "living curriculum" outside the regular classroom that is connected to students' lives and that contributes to building a dynamic and authentic community of learners.

\section{Phase 3: Emergence of a More Integrative, Inclusive Sense of Self as Teacher and Learner}

The numerous disorienting dilemmas experienced by the interns in Greece, as they navigated new psychological, cultural, and education terrains associated with their internship at ACS-Athens, challenged them to re-examine their educational assumptions and shift their frames of reference. A more integrative, inclusive sense of self as "teacher" and "learner" began to emerge. Their final reflections are evidence of a personal, professional, and emotional transformation as they prepare for their return flight to Canada.

Camille, a senior English major and published poet, eloquently expresses, through the metaphor of a deck of cards, the multiple emotional transformations she has undergone at ACSAthens, and the difficulty experienced integrating "the other person" she became in Greece with her current Canadian persona upon return to Winnipeg. She speaks of her Greek experiences in third person, ascribing a surreal element to her international practicum. At the conclusion of the internship, the "blur" of cards finally comes to a rest.

\section{Emotion like a deck of cards}

The following is a story about growth, emotion, revelation, and eyes. It is a story about becoming, about seeing clearly. More clearly, at least. This is not really a story. There is no plot. This is not a narrative. There is neither time nor place here to detail the day-to-day happenings that built my experience in Greece.

This moment. When everything that had happened in the past few weeks fell into place and made sense; became part of a synchronized whole that was recognizable as something unique and complete, like a shuffled deck of cards coming to rest and being still and being identifiable as a deck of cards rather than a blur of motion. Emotion.

This moment. The instant when the deck of cards stopped moving. The pause and intake of breath after the flood of happening. The cascade of memories becoming bigger than their sum.... Specific moments stand out, but what meaning they have apart from the body of time and experience is not yet known. She sees. She feels. She knows. These things bring wisdom and melancholy. That woman, international woman, died too soon. And the rest cannot be spoken. It is too deep and has not yet bubbled to the surface of the 
new woman. Both understand what was and how it came to be, but the horizon is too close. Time will bring perspective, and the ability to tell her story in more concrete words.

For now, there is emotion. There is joy. There is mourning. There is gratitude. So much gratitude. There is contentment... awe... and wonder. (Camille, journal entry, May, 2008)

Dalia looks back upon her experiences at ACS-Athens and is compelled to re-evaluate her original assumptions and beliefs. She realizes that Greece has afforded her a lifetime of insights and reflections, although she is not yet able to articulate how this will influence her life's path.

\section{A re-evaluation of my assumptions}

Being in a new cultural setting is an unforgettable experience. Your characteristic way of seeing the world is constantly confounded, and you are left with the arduous, but rewarding task of re-evaluating your assumptions and beliefs about ...the teaching and learning process ... and testing them against a radically different context at the private, American Community School in Athens. ...I worked hard, I enjoyed myself, I learned every single day. I have come home with memories, friendships, pictures, drawings, certainty, and confusion. I would not trade the experience for anything in the world. Greece has provided me with a lifetime of insights and reflection, and that has changed the very trajectory of my life. (Dalia, journal entry, May 27, 2008)

Leila highlights what it feels to be culturally dislocated as an intern in Athens and admits that she has never been in a position of outsider before. Interning at ACS-Athens has given her insight into how newcomers to Canada must feel.

\section{In the place of an outsider}

I think one of the major ideas that was so important to my teaching block at ACS was that of culture and being placed in the position of newcomer...as I have not ever been the outsider in a culture before. This has given me a better idea about how newcomers to our country feel upon their arrival. Of course, I was lucky to have a great deal of support in finding an apartment, navigating my way around Athens and at the school, but there were certainly times when language was a barrier for me.... I was able to take what I have learned in my five years of education, but also have the incredible opportunity to learn things that I really feel go beyond what can be learned through University classes, or even through the practicum at your neighbourhood school. I would not trade this experience for the world! (Leila, journal entry, May, 2011)

Lauren is grateful for her experience at ACS-Athens. She has grown in many ways and feels empowered - almost incredulous of her accomplishments, acknowledging personal change and enrichment as she prepares to return to Canada.

\section{Growth without the constraints of comfort}


Being in Athens...gave me a sense of independence and confidence that I really could overcome obstacles and survive in a country that was not my own, without anything familiar around me....This trip has made me realize that if you have a goal, a dream, or a vision, and if you just believe in it and work hard towards it each day-it can materialize. Stepping out of my life and into a new experience really challenged my way of thinking and allowed me to grow without the constraints of being comfortable in my surroundings.... I have learned and grown more than I could have ever imagined through my time in Greece, on a professional, educational and personal level. I feel a sense of gratitude and thanks for every moment that I have experienced, and know that I will return a different person than I was when I left. (Lauren, journal entry, March 27, 2011)

The student teachers' positive experiences in Athens leave them energized and optimistic about their future in teaching. Their revealing insights reflect the dynamic interplay between emotions and perspective transformation. A new sense of confidence, an appreciation of their unique practicum experience, and a depth of intercultural awareness emerge. Interestingly, a number of the stages first outlined by Mezirow (1981) are reflected in the teacher candidates' journals. They provide a unique insight into significant personal learning associated with an international practicum that can inform teacher preparation and the important role of practicum placement; the cooperating teacher as mentor; and the psychological, social, and cultural landscape of student teachers trying to master the art and practical science of teaching.

\section{Discussion}

Few studies have explored student teacher experiences within the framework of transformative learning theory. The current study provides support for the utility of Mezirow's model for understanding the challenges faced by preservice teachers who intern overseas. Balancing the multiple disorienting dilemmas of a new classroom, the high expectations of an IB school culture, and the pedagogical demands of teaching a largely English as a Foreign Language (EFL) student population-all against the backdrop of the broader context of an unfamiliar Greek culture-provided the Canadian interns in this study with a number of discomforting challenges. Dalia, for example, discovers that many of her students at ACS-Athens are from families of privilege, unlike those she has taught in Winnipeg. Anne tries to reconcile the devaluation of homework that she has encountered in Canadian schools with ACS-Athens' approach. She also compares the negative elements of peer pressure, which she is accustomed to seeing in Canadian schools, with the more positive, energizing, and inclusive peer pressure, which she sees exemplified at ACS-Athens. Lindsey comments on the many dynamic and creative learning opportunities offered to students at ACS-Athens - an emphasis which she would like to see in Winnipeg schools. Over the 5-week period, interns began to re-evaluate their frames of reference. They began to reframe their identity so that it was more integrative and inclusive, and sensed, but could not always articulate, the long-term impact that their experiences in Greece would have on their lives. They developed an adaptive capacity that enabled them to respond to the multiple demands of an unfamiliar culture. The many disorienting dilemmas challenged the interns to think differently about their original assumptions and beliefs. For example, Camille eloquently expressed, through the metaphor of a deck of cards, the multiple emotional transformations she had undergone at ACS-Athens. Dalia looked back upon her experiences at ACS-Athens and was compelled to re-evaluate her original assumptions and beliefs. Lauren 
highlighted what it felt to be culturally dislocated as an intern in Athens and admitted that she had never been in a position of outsider before. Lauren felt an increasing sense of empowerment as her Greek odyssey came to a close.

Each narrative highlighted above represents a unique experience of student teaching in an international setting. The experiences of the ACS-Athens interns, as reflected in their personal observations, suggest that learning is complex and multi-dimensional. Transformative learning, as Clark (1993) observes, is a deeper-level learning that shapes and changes a person unlike other learning experiences. Rossiter (1999) emphasizes that narrative writing of significant learning experiences can encourage adults to not only reflect upon and interpret their life, but also to change it. Emotions such as fear, anxiety, and joy are referred to frequently in the narratives; the interns each comment on their learning experiences not only in terms of gaining academic and cultural knowledge, but also in terms of their own emotional growth. Their views of the potential of education and the role of the educator as a catalyst, change agent, and facilitator emerge.

A central feature of transformative learning, as Karpiak (2003) notes, is "critical selfreflection, a process whereby adults examine cultural and individual assumptions and meanings that underlie and shape their view of life" (p. 101). While learning involves cognitive and rational processes, it can also include intuitive, expressive, creative, and emotional dimensions. Within educational contexts, a student teacher's experience can include growth and development that reflects many dimensions of learning. The journey of transformative learning depends upon factors such as personality, learning style, and learner readiness. The student teachers in this study were fortunate to work in an educational climate that valued and nurtured experiential learning and critical reflection. In the narrative data of this study, numerous references are made to specific experiential and authentic learning activities that were encouraged, such as drama projects and productions, debate, presentations, and exploring classic literature in unique ways can lead to an enriched and creative learning experience.

\section{Students' Mentoring Journeys: Modeling Ways of Being and Thinking.}

Perspectives of teaching and learning that emerged from this study may also be compared to the apprenticeship model of learning, as outlined by Pratt and associates (1998). Johnson and Pratt (1998) describe this perspective as "modeling ways of being and thinking" (p. 83). The mentor teachers at ACS-Athens were described by the student teachers as being an expert or model teacher. They possess expertise, empathy, and enthusiasm-important qualities in exemplary teachers (Brookfield, 2010; Daloz, 2000; Goleman, 1998). The apprenticeship perspective of teaching is most often applied, they note, in teaching specific tasks (e.g., building a car or conducting a medical procedure), but it is, as the authors note, increasingly used in "intellectual apprenticeships" to develop master practitioners in disciplines and practices characterized by great complexity, multiple procedures, and dynamic environments (e.g., medicine, police work, and professional development). Johnson and Pratt (1998) draw upon cognitive and constructivist learning theories to develop their model. Situated cognition emphasizes the way learners "build, revise, and integrate their schemas related to the tasks and relations of their work or communities; but simultaneously, the community of people also changes" (p. 83). Katerina's narrative, for example, reflects the way that her own expertise as a drama student at university was challenged and extended in Athens because she had an opportunity to work with an IB Drama specialist who experimented with many different forms of 
theatre. Once she overcame her fear and insecurity, Katerina was able to experience fully being a teacher and a co-learner in a collaborative venture. Indeed many of the narratives reflect learning that involves self-awareness, emotional insight and growth, and building new academic knowledge. Student teachers such as Katerina had the benefit of working with both "maestro and mentor" teachers. Clark, Triggs, and Nielsen (2014) explain that "maestro" teachers "love to teach, emphasize content delivery, offer feedback, and are happy to model teaching practice. In contrast, mentors discuss and analyze events and observations with interns and offer time and opportunities for guided [practice] rather than mimicking practice" (p. 23).

\section{The Role of Master Teachers}

The ACS-Athens school clearly values diversity and excellence in teaching; a strong academic curriculum is also balanced with enriching experiential learning opportunities. The cultural climate of the school nurtures intellectual and personal development. Cultural and academic exchanges are welcomed and viewed as an opportunity to expand learning horizons. A rich emphasis on history, drama, literature, and the sciences has an interdisciplinary and international focus. There is a high expectation that their students will succeed and become professional leaders in the community. The students at ACS-Athens are privileged and have an array of opportunities to develop personally, academically, socially, and culturally. The student teachers in this study had the opportunity to work with master teachers who had a comprehensive body of organized and relevant content and procedural knowledge.

Master teachers "not only act from extensive knowledge and elaborately textured schemas, they are also able to adapt successfully to unusual and problematic situations of practice (Clark, Triggs, \& Nielsen, 2014). In other words, they can transcend the limits of a single situational context and bring to practice a tacit knowing in new situations" (Johnson \& Pratt, 1998, p. 95). Dinah describes feeling "privileged to have experienced the unique team teaching Humanities courses offered to the students at ACS." She views both her mentor teachers as positive role models. Though they gave her suggestions and constructive feedback, she was also encouraged to be self-directed and creative in her teaching.

Consistent with the experience detailed by Dinah, Johnson and Pratt (1998) emphasize that the apprenticeship model of learning is not a "one way" street or simply a "transmission" of ideas from the expert mentor to the novice mentee. Rather, there is a two-way complex dynamic of learning that involves a mutual valuing of ideas and an exchange of insights. This process, note the authors, is active rather than passive; it is social, cooperative, collaborative, and authentic (p. 89). Exploring the diversity of teaching approaches that promote transformative learning can open up new instructional avenues that encourage greater complexity and creativity in teaching (Magro, 2009; Magro \& Polyzoi, 2009).

\section{Working Towards Transformative Learning.}

In his book, The Courage to Teach, Parker Palmer (2007) writes about the need to address the emotional landscape of teaching; too often, teaching occurs in isolation and individual teaches are reluctant to address their fears, challenges, or institutional barriers that impede their intent to be more creative in teaching concerns. These apprehensions often go unspoken and, as a result, significant educational change initiatives may not occur (Palmer, 2007). If we are to encourage a context for reflection, creativity, and educational transformation, a cultural shift is needed in educational leadership. This leadership would welcome and support 
dialogue, critical reflection, experimentation, and professional growth that would lead to greater equity and inclusion at all levels of education. Rather than the educational organizations being closed systems, a transformative educational system would be open to dynamic change and development. It is also important to emphasize that both preservice and in-service teachers are adult learners; the rich body of literature that continues to emerge in the field of adult education suggests that teacher educational programs could be improved if a model of adult learning could be applied to courses and practicum experiences. This perspective would take into account key principles of adult learning: recognizing diversity and building upon the prior experience of adult learners, providing choice, encouraging self-direction, providing opportunities for inquiry-based learning and dialogue, and providing opportunities to think more reflectively and critically (Chickering, Dalton, \& Stamm, 2006; King, 2005; Merriam, Courtenay, \& Cevero, 2006; Mezirow, \& Associates, 2000).

\section{Future Research}

This study suggests that student teachers can benefit from having expert mentor teachers who value risk taking, creativity, and academic excellence that is balanced with experiential learning. We acknowledge that the current study is based on a relatively small number of participants interning at an international IB school in Athens; thus, generalizing the findings to other schools and other cultural contexts may be limited. Comparing greater numbers of student teachers' experiences across different school districts locally, nationally, and internationally, and among diverse cultural contexts may serve to enrich the body of literature in this area. A further exploration of the philosophies of cooperating/mentor teachers and their impact on student teachers' educational perspectives and teaching styles could inform studies like the present one in valuable ways (Clark, Triggs, \& Nielson, 2014).

The current study raises a number of additional questions that may serve as the basis for future research. For example:

1. What is the student's role in fostering transformative learning? What are his/her responsibilities in relationship to the transformative educator? How does a student's transformation affect fellow-classmates, the teacher, and the educational institution? What impact does fostering transformative learning have on learning outcomes (e.g., grades, test scores). (Taylor, 2008)

2. How might specific courses and programs at university that prepare student teachers inhibit or encourage transformative types of teaching and learning? What professional development programs are in place that would help both preservice and in-service teachers learn more about transformative teaching and learning?

3. What preparation do student teaching practicum supervisors and cooperating teacher need in understanding the dynamics of transformative learning and its link to creative and critical thinking? How can teacher education programs encourage more reflection?

4. How do factors such as personality, teaching style, student attitude and skill, specific subject areas, and educational resources encourage or inhibit transformative learning and teaching?

5. How might case studies of exemplary schools like ACS-Athens help inform program planning in other schools? 
6. How are cooperating teachers and university practicum supervisors selected? How knowledgeable should they be about the potential and promise of transformative learning in professional educational contexts?

7. How can links between transformative learning and creative approaches to teaching and learning be strengthened?

8. How can international student teaching practica foster intercultural intelligence?

\section{Conclusions}

This study highlights the inner landscape of student teachers' experiences within the framework of transformative learning theory (Dirkx, 2012; Taylor, 2008). It informs the literature on transformative learning theory by applying the ideas and conceptions to student teaching experiences in international practica. There are few studies that apply transformative theory to the experiences of preservice teachers. This exploratory investigation suggests that cultural background, personality, motivation, and the values that guide one's decision making in teaching can impact significant personal learning (Brookfield, 1995; Mezirow, 2000; Taylor, 2008). More opportunities for student teachers to detail and narrate their experiences may be beneficial and may result in an enriched level of learning. Rather than feeling disempowered, silenced, or discouraged as a result of student teaching experiences, working in a creative learning environment may contribute to student teachers' gaining a more optimistic vision of the power of education to affect change in positive ways. The narratives presented in this study capture the complexity, uncertainty, and uniqueness of student teaching (Brookfield, 1995; Daloz, 2000; Schon, 1983). They provide a starting point to explore further the psychological dimensions of learning among preservice teachers. 


\section{References}

Boyd, R. D., \& Myers, J. G. (1988). Transformative education. International Journal of Lifelong Education, 7(4), 261-284.

Britzman, D. (1998). Lost subjects, contested objects: Toward a psychoanalytic inquiry of learning. Albany, NY: State University of New York.

Brookfield, S. (1995). Becoming a critically reflective teacher. San Francisco, CA: Jossey-Bass.

Brookfield, S. (2000). Transformative learning as ideology critique. In J. Mezirow \& Associates (Eds.), Learning as transformation (pp. 125-150). San Francisco: Jossey-Bass.

Brookfield, S. (2010). The skillful teacher. San Francisco, CA: Jossey-Bass.

Chickering, A. W., Dalton, J. C., \& Stamm, L. (2006). Encouraging authenticity and spirituality in higher education. San Francisco, CA: Jossey-Bass.

Clark, C. (1993). Transformational learning. In S. Merriam (Ed.), An update on adult learning theory (pp. 47-56). San Francisco, CA: Jossey-Bass.

Clarke, A., Triggs, V., \& Nielsen, W. S. (2014). Cooperating teacher participation in teacher education: A review of the literature. Review of Educational Research, 84(20), 163-202.

Cranton, P. (2006). Understanding and promoting transformative learning. San Francisco, CA: Jossey-Bass.

Cross, P. (1981). Adults as learners. San Francisco, CA: Jossey-Bass.

Daloz, L. (2000). Transformative learning for the common good. In J. Mezirow \& Associates (Eds.), Learning as transformation: Critical perspectives on a theory in progress (pp. 103-124). San Francisco, CA: Jossey-Bass.

Dirkx, J. M. (2012). Nurturing soul work: A Jungian approach to transformative learning. In E. Taylor \& P. Cranton (Eds.), The handbook of transformative learning (pp. 116-130). San Francisco, CA: Jossey-Bass.

Dominice, P. (2000). Learning from our lives: Using educational biographies with adults. San Francisco, CA: Jossey-Bass.

Freire, P. (1997). Pedagogy of the oppressed. New York, NY: Seabury Press.

Goleman, D. (1998). Working with emotional intelligence. New York, NY: Bantam.

Johnson, J., \& Pratt, D.D. (1998). The apprenticeship perspective: Modeling ways of being. In D. D. Pratt \& Associates (Eds.), Five perspectives of teaching in adult and higher education (pp. 83-104). Malabar, FL: Krieger.

Karpiak, I. (2003). The ethnographic, the reflective, and the uncanny: Three "tellings" of autobiography. Journal of Transformative Education, 1(2), 99-116.

Kelly, B. M., (2009). Educational enrichment: An extra program or essential method of instruction? Ethos, 3(2), 27-28. 
Kelly, D. (2012). Teaching for social justice: Translating an anti-oppression approach into practice. Our Schools/Our Selves, 21(12), 135-154.

King, K. (2005). Bringing transformative learning to life. Malabar, FL: Krieger.

Lincoln, Y., \& Guba, E. (1985). Naturalistic inquiry. London, UK: Sage Publications.

Magro, K. (2009). Integrating emotional and social intelligence in English language arts education. Talking Points, 20(2), 2-9.

Magro, K., \& Polyzoi, E. (2009). Geographical and psychological terrains of adults from waraffected backgrounds. Journal of Transformative Education, 7(1), 85-106.

Merriam, S. B., \& Associates (2002). Qualitative research in practice. San Francisco, CA: Jossey-Bass.

Merriam, S. B., Courtenay, B., \& Cevero, R.M. (Eds.), (2006). Global issues and adult education. San Francisco, CA: Jossey-Bass.

Mezirow, J. (1981). A critical theory of adult learning and education. Adult Education Quarterly, 32(1), 3-24.

Mezirow, J. (1990). How critical reflection triggers transformative learning. In J. Mezirow \& Associates (Eds.), Fostering critical reflection in adulthood: A guide to transformative and emancipatory learning (pp.1-21). San Francisco, CA: Jossey-Bass.

Mezirow, J. (2000). Learning to think like an adult. In J. Mezirow \& Associates (Eds.), Learning as transformation (pp. 3-34). San Francisco, CA: Jossey-Bass.

Mezirow, J. (2012). Learning to think like an adult. In E.Taylor \& P. Cranton (Eds.), The handbook of transformative learning (pp. 73-95). San Francisco, CA: Jossey-Bass.

Mezirow, J., \& Associates (2000). Learning as transformation: Critical perspectives on a theory in progress. San Francisco, CA: Jossey-Bass.

O’Sullivan, E., Morrell, A., \& O’Connor, M. (2002). Expanding the boundaries of transformative learning. London, UK: Palgrave Press.

Palmer, P. (2007). The courage to teach: Exploring the inner landscapes of a teacher's life. San Francisco, CA: John Wiley \& Sons.

Pratt, D. \& Associates (1998). Five perspectives of teaching in adult and higher education. Malabar, FL: Krieger.

Rossiter, M. (1999). Understanding adult development as narrative. In M. C. Clark \& R. S. Caffarella (Eds.), An update on adult developmental theory: New ways of thinking about the life course (New directions for adult and continuing education, (No. 84, pp.77-85). San Francisco, CA: Jossey-Bass.

Schön, D. A. (1983). The reflective practitioner: How professionals think in action. New York, NY: Basic Books. 
Taylor, E. (2008). Transformative learning theory. In S. B. Merriam (Ed.). Third update on adult learning theory (New directions for adult and continuing education, (No. 119, pp. 5-16). San Francisco, CA: Jossey-Bass.

Taylor, E., \& Cranton, P. (Eds.). (2012). The handbook of transformative learning: Theory, research, and practice. San Francisco, CA: Jossey-Bass.

Van Manen, M. (1997). Researching lived experiences. Edmonton, AB: The Althouse Press.

Wolk, S. (2009). Reading for a better world: Teaching for social responsibility. Journal of Adolescent and Adult Literacy, 52(8), 667-682. 